\title{
Is There a Possible Association between Skeletal Face Types and Third Molar Impaction? A Retrospective Radiographic Study
}

\author{
Melek Tassoker ${ }^{\mathrm{a}}$ Hatice Kok ${ }^{\mathrm{b}}$ Sevgi Sener ${ }^{\mathrm{a}}$ \\ a Department of Oral and Maxillofacial Radiology, Faculty of Dentistry, Necmettin Erbakan University, Konya, Turkey; \\ ${ }^{\mathrm{b}}$ Department of Orthodontics, Faculty of Dentistry, Necmettin Erbakan University, Konya, Turkey
}

\section{Significance of the Study}

- This study aimed to investigate the relationship between third molar impaction and different skeletal face types. We observed that mandibular third molar impactions are associated with different facial skeletal types while maxillary third molar impactions are not related to face type.

\section{Keywords}

Tooth, impacted $\cdot$ Molar, third $\cdot$ Cephalometry

\section{Abstract}

Objective: Third molar impaction is seen much more than impaction of any other tooth as they are the last teeth to erupt. Inadequate retromolar space and the direction of eruption may be contributing factors. The aim of this study was to investigate the relationship between third molar impaction and different skeletal face types. Subjects and Methods: Panoramic and lateral cephalometric radiographs of 158 orthodontic patients (aged 19-25 years) were retrieved from the archived records of the Necmettin Erbakan University Faculty of Dentistry, Konya, Turkey. Third molar impaction was classified on the basis of Winter's classification. The skeletal facial type was determined by a measure of the angle created by the lines Ba-Na and Pt-Gn. The mean was $90 \pm 2$ and this value was regarded as mesofacial. An angle of $>93^{\circ}$ was regarded as brachyfacial and an angle of $<87^{\circ}$ as dolichofacial. Results: The overall presence of mandibular and maxillary third molar impactions was 65.2 and $38.6 \%$, respectively. Although there was a statistically significant difference between different skeletal facial types and mandibular third molar impaction ( $p<0.05$ ), no statistically significant differences were observed between different skeletal facial types and maxillary third molar impaction $(p>0.05)$. Brachyfacials demonstrated a lower prevalence of third molar impaction than dolichofacials. Conclusions: Different skeletal face types were associated with mandibular third molar impaction. Brachyfacials, who have a greater horizontal facial growth pattern than dolichofacials, showed a lower prevalence of impacted mandibular third molars.

(c) 2018 The Author(s)
Published by S. Karger AG, Basel

\section{Introduction}

Third molars are the most frequently impacted teeth [1-6]. The prevalence of their impaction is highly variable and generally reported to be between 16.7 and $73.82 \%$ [5]. Impaction is more common in the mandibles than in the

\section{KARGER}

E-Mail karger@karger.com www.karger.com/mpp (c) 2018 The Author(s) Open access

This is an Open Access article licensed under the Creative Commons Attribution-NonCommercial-4.0 International License (CC BY-NC) (http://www.karger.com/Services/OpenAccessLicense), applicable to the online version of the article only. Usage and distribution for commercial purposes requires written permission.
Melek Tassoker

Department of Oral and Maxillofacial Radiology

Faculty of Dentistry, Necmettin Erbakan University

TR-42050 Konya (Turkey)

E-Mail dishekmelek@gmail.com 


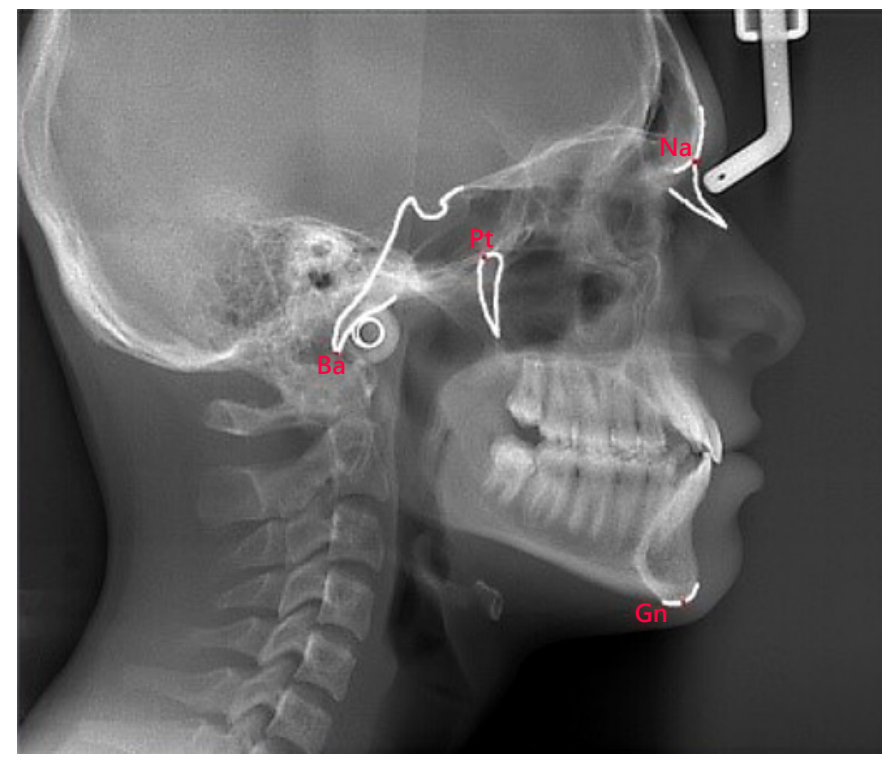

Fig. 1. The cephalometric landmarks used in the study.

maxilla [7], and its prevalence is higher in females [8]. If third molars are not impacted, they erupt between the ages of 17 and 21 years [3].

The decision to extract third molars, commonly known as "wisdom teeth," should be made based on well-defined criteria. Impacted third molars may be related to pathological processes ranging from dental caries and root resorption to pericoronitis, cysts, and neoplasms. Additionally, they are blamed for mandibular incisor crowding after orthodontic treatment [9].

Inadequate retromolar space was found to be an important etiological factor for mandibular third molar impaction $[10,11]$. Lack of retromolar space is due to an insufficient amount of mandibular growth. Additionally, it can be related to the direction or rotation of growth, which determines the type of face (mesofacial, brachyfacial, or dolichofacial) [4]. Facial growth can help predict mandibular third molar eruption [12]. The facial skeleton grows in a forward and downward direction under normal conditions. In a mesofacial growth pattern, there is relative harmony in these two directions. The term "brachyfacial" is used to describe an individual with a short anterior face height and a wide face. "Dolichofacial" is the term used to describe a long anterior face height and a narrow face $[3,6,12]$.

Third molar impaction has been found to be related to some dental and skeletal features that are controversial and differing among varying populations [4]. The aim of this study was to investigate the relationship between

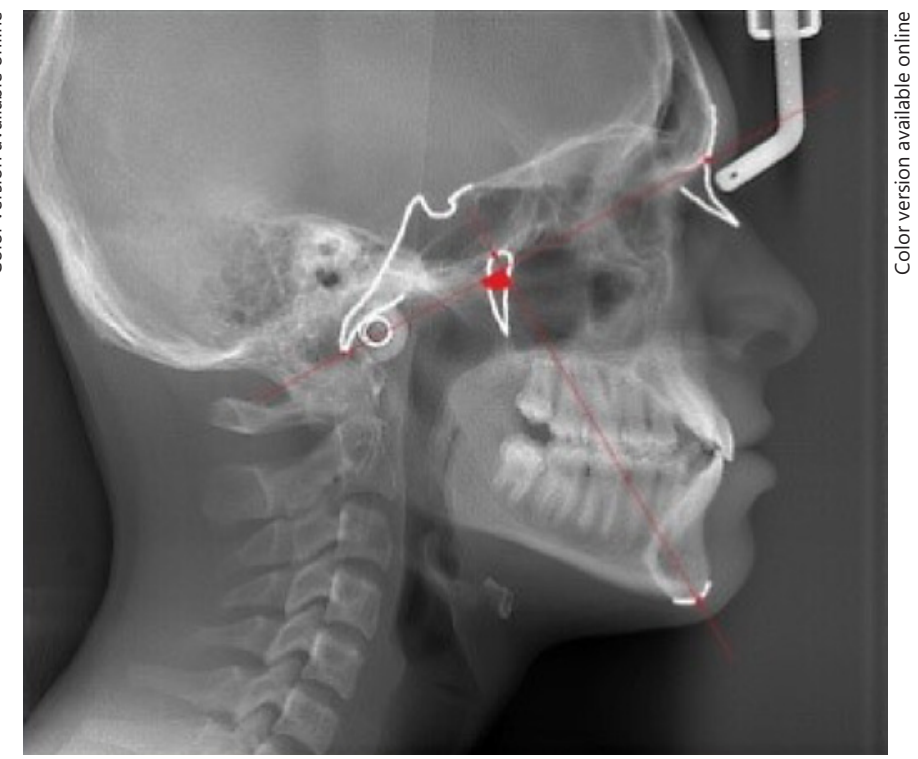

Fig. 2. The cephalometric lines and facial axis angle.

third molar impaction and different skeletal face types. The null hypothesis was that there is no relationship between third molar impaction and skeletal face type.

\section{Subjects and Methods}

\section{Study Design and Sample}

The study sample consisted of archived digital lateral cephalometric and panoramic radiographs of 158 individuals (61 males and 97 females) aged 19-25 years who had visited the Department of Orthodontics, Faculty of Dentistry, Necmettin Erbakan University between 2014 and 2016. Digital lateral cephalometric and panoramic radiographs were obtained using a J. MORITA machine (2D Veraviewepocs ${ }^{\circledR}$, MFG Corp., Kyoto, Japan) with a tube voltage of $65-90 \mathrm{kV}$ and a tube current of 5-10 mA. Included in this study were the pretreatment records of patients with the presence of third molars that had complete root formation and were either fully erupted or impacted, no history of maxillofacial trauma, no previous orthodontic treatment, no missing or extracted permanent teeth, no maxillofacial involvement with endocrine dysfunction, and nonsyndromic conditions.

\section{Evaluation of Images}

All cephalometric radiographs were traced and analyzed by the same orthodontist (H.K.) using the Planmeca Romexis ${ }^{\circledR}$ (Helsinki, Finland) Cephalometric Analysis Module. The skeletal facial type was determined by a measure of the angle created by the lines Ba$\mathrm{Na}$ and Pt-Gn (Fig. 1,2). The mean was $90 \pm 2^{\circ}$ and this value was regarded as mesofacial. An angle of $>93^{\circ}$ was regarded as brachyfacial and an angle of $<87^{\circ}$ as dolichofacial [3].

The cephalometric landmarks used to determine skeletal facial type (Fig. 1, 2) were as follows: $\mathrm{Ba}$ - the most inferior posterior point of the occipital bone at the anterior margin of the occipital 

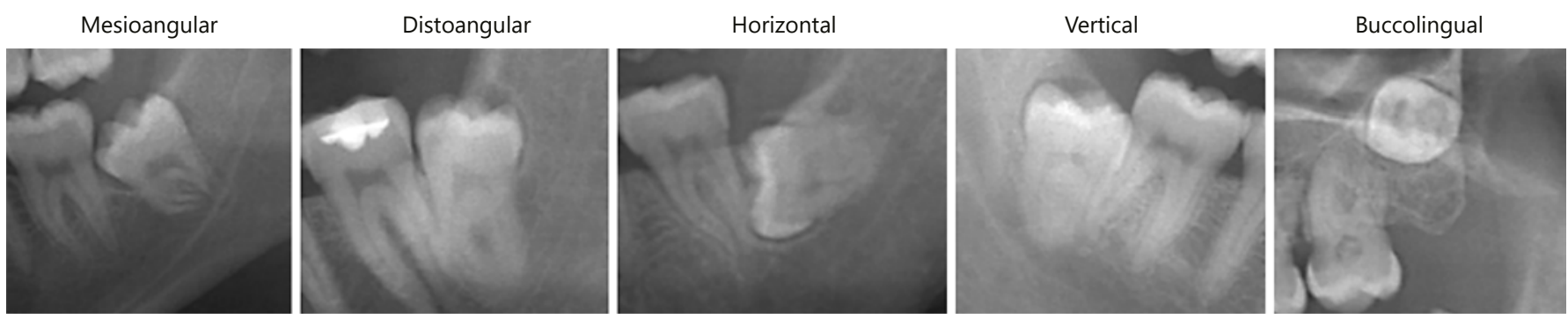

Fig. 3. Cropped digital panoramic radiographic examples of Winter's classification.

foramen; $\mathrm{Na}$ - the most anterior point of the nasofrontal suture in the midsagittal plane; Pog - the most anterior point on the midsagittal symphysis; $\mathrm{Gn}$ - a cephalometric landmark formed by the intersection of the tangent to the most inferior point on the inferior border of the symphysis and the most inferior point of the gonial region and the line connecting $\mathrm{Na}$ and $\mathrm{Pog}$; and $\mathrm{Pt}$ - located at the lower border of the foramen rotundum, which is observed at the root of the pterygoid plates at the lower border of the body of the sphenoid bone.

Digital panoramic radiographs were used to evaluate the position and angulation of impacted third molars. Maxillary and mandibular third molar impactions were classified according to Winter's classification [13] (mesioangular, horizontal, vertical, distoangular, and buccolingual) (Fig. 3).

\section{Statistical Analysis}

The means and standard deviations of all variables were calculated. The $\chi^{2}$ test was used to determine the relationship between third molar impactions and different skeletal face types. Intraobserver reliability was determined by Cohen's $\kappa$ analysis and intraexaminer reliability was interpreted as almost perfect (0.81-1.0) according to Landis and Koch [14]. All statistical analyses were performed using IBM SPSS statistics 21.0 (IBM Corp, Armonk, NY, USA). $p$ values $<0.05$ were considered significant.

\section{Results}

Of the 158 patients, $38.6 \%$ were male and $61.4 \%$ female. The mean age of the study sample was $20.19 \pm 1.62$ years $(20.47 \pm 1.75$ years for females and $19.74 \pm 1.30$ years for males). The majority of individuals had a dolichofacial pattern $(46.2 \%)$. There was no relationship between skeletal face types and $\operatorname{sex}(p>0.05, p=0.52)$. The distribution of skeletal facial types according to sex is given in Table 1.

The overall presence of mandibular and maxillary third molar impaction was 65.2 and $38.6 \%$, respectively. Although there was a statistically significant difference between different skeletal face types and mandibular third molar impaction $(p<0.031)$, no statistically signifi-
Table 1. Facial type distribution according to sex

\begin{tabular}{|c|c|c|c|c|c|c|}
\hline \multirow[t]{2}{*}{ Skeletal face type } & \multicolumn{2}{|c|}{ Males } & \multicolumn{2}{|c|}{ Females } & \multicolumn{2}{|c|}{ Total } \\
\hline & $n$ & $\%$ & $n$ & $\%$ & $n$ & $\%$ \\
\hline Mesofacial & 17 & 27.8 & 40 & 41.2 & 57 & 36.1 \\
\hline Dolichofacial & 28 & 45.9 & 45 & 46.4 & 73 & 46.2 \\
\hline Brachyfacial & 16 & 26.2 & 12 & 12.4 & 28 & 17.7 \\
\hline Total & 61 & 100.0 & 97 & 100.0 & 158 & 100.0 \\
\hline
\end{tabular}

cant differences were observed between different skeletal face types and maxillary third molar impaction $(p=$ 0.833 ). Brachyfacials demonstrated a lower prevalence of maxillary and mandibular third molar impaction compared to dolichofacials and mesofacials. The distribution of third molar impaction according to skeletal face type is given in Table 2.

The distribution of third molar impaction angulation is given in Table 3. The most prevalent impaction position was mesioangular in the mandible and distoangular in the maxilla. No statistically significant relationship was found between skeletal facial type and the angular positions of teeth $(p>0.05)$.

\section{Discussion}

Third molar prognosis is an important issue for orthodontists in planning successful treatment [4]. Orthodontists should take into consideration the presence or absence of third molars, especially in terms of the possibility of eruption or impaction when distalization is required for first or second molars, the repercussion of the extraction of premolars or other permanent teeth in their positioning, and the timing of the orthodontic treatment [9]. Our results showed that the overall rate of mandibular 
Table 2. Distribution of third molar impaction according to skeletal face type

\begin{tabular}{|c|c|c|c|c|c|}
\hline \multirow{2}{*}{\multicolumn{2}{|c|}{ Third molar impaction }} & \multicolumn{3}{|c|}{ Skeletal face type } & \multirow[t]{2}{*}{ Total } \\
\hline & & mesofacial & dolichofacial & brachyfacial & \\
\hline \multirow[t]{2}{*}{ Maxilla } & absence & $36(37 \%)$ & $43(44 \%)$ & $18(19 \%)$ & $97(100 \%)$ \\
\hline & presence & $21(34 \%)$ & $30(49 \%)$ & $10(17 \%)$ & $61(100 \%)$ \\
\hline \multirow[t]{2}{*}{ Total } & & $57(36 \%)$ & $73(46 \%)$ & $28(18 \%)$ & $158(100 \%)$ \\
\hline & & & $p>0.05, p=$ & & \\
\hline \multirow[t]{2}{*}{ Mandible } & absence & $23(42 \%)$ & $18(33 \%)$ & $14(25 \%)$ & $55(100 \%)$ \\
\hline & presence & $34(33 \%)$ & $55(53 \%)$ & $14(14 \%)$ & $103(100 \%)$ \\
\hline \multirow[t]{2}{*}{ Total } & & $57(53 \%)$ & $73(46 \%)$ & $28(18 \%)$ & $158(100 \%)$ \\
\hline & & & $p<0.05, p=$ & & \\
\hline
\end{tabular}

Table 3. Distribution of third molar impaction angulation according to Winter [13]

\begin{tabular}{lcccc}
\hline $\begin{array}{l}\text { Impacted third } \\
\text { molar position }\end{array}$ & 18 & 28 & 38 & 48 \\
\hline Mesioangular & $28(18 \%)$ & $17(11 \%)$ & $89(89 \%)$ & $98(62 \%)$ \\
Distoangular & $36(23 \%)$ & $28(18 \%)$ & $2(2 \%)$ & $1(0.5 \%)$ \\
Vertical & $7(4 \%)$ & $5(3 \%)$ & - & - \\
Buccolingual & $1(0.6 \%)$ & - & $1(1 \%)$ & $1(0.5 \%)$ \\
Horizontal & - & - & $8(8 \%)$ & $6(4 \%)$ \\
Not impacted & $86(54.4 \%)$ & $108(68 \%)$ & $58(37 \%)$ & $52(33 \%)$ \\
\hline Total & $158(100 \%)$ & $158(100 \%)$ & $158(100 \%)$ & $158(100 \%)$ \\
\hline
\end{tabular}

and maxillary third molar impaction was 65.2 and 38.6\%, respectively. This higher rate of impaction may be a result of the study population consisting of orthodontic patients who are more likely to suffer from malocclusion and potential crowding and so are likely to have a higher presence of third molar impaction than a random population sample [3].

Various studies have been conducted to ascertain the etiology of third molar impaction. Many researchers [3, $9,12,15-17$ ] have claimed that greater mesial crown inclinations of third molars seem to be indicative of mandibular third molar impaction. Similarly, in this study, mesial inclination of the mandibular third molar and distal inclination of the maxillary third molar were found to be indicative of the tendency for these teeth to be impacted. Mollaoglu et al. [18] reported that individuals with mesioangular tooth inclination had insufficient space in the retromolar region.

Genetic factors and eating habits have also been blamed for impaction [9]. Second molar extraction [19] and premolar extraction for orthodontic treatment [20] decreased third molar impaction. Late third molar maturation combined with early physical maturation [21], the size, growth amount, and direction of the mandible [10], the remodeling and width of the ramus, the rate of third molar maturation, the inclination of posterior dentition, and the size of dentition relative to the jaws have all been discussed as other implicated factors [4]. Hassan [4] claims that different samples and methods were used in previous studies, which may have led to the different findings.

The current study was designed to ascertain whether skeletal facial growth patterns are related to third molar impaction. The skeletal face types of the subjects were determined using lateral cephalometric radiographs, which provide analysis of craniofacial growth, maxillofacial deformities, and orthodontic problems [22]. Our findings showed that mandibular third molar impaction was 1.5 times more common in dolichofacials than in brachyfacials. This can be attributed to the vertical direction of the condyle, which is present in dolichofacial individuals. These results are consistent with the results of Breik and Grubor [3], who concluded that individuals with a brachyfacial facial growth pattern showed a twice lower incidence of third molar impaction than individuals with a dolichofacial growth pattern. This was explained by the fact that the growth potential is greater in a brachyfacial growth pattern, which allows more remodeling resorption of the anterior border of the ramus.

Capelli [9] claimed that third molar impaction was more likely to occur in vertically growing mandibles. A long, ascending ramus and short mandibular length seem to be indicative of mandibular third molar impaction. The mandibular length was shorter in the dolichofacial facial growth pattern, consistently supporting the hypothesis that dolichofacial individuals have an increased risk of third molar impaction [23]. 


\section{Conclusion}

The null hypothesis that there is no relationship between third molar impaction and skeletal face type was rejected. Patients with a predominantly horizontal growth pattern (brachyfacials) had a lower prevalence of mandibular third molar impaction compared to those with a predominantly vertical growth pattern (dolichofacials). Since third molars can change their position and continue to erupt from their current position, further prospective studies providing greater understanding of third molar impaction should be done to observe possible inclination changes of third molars in this age group.

\section{Statement of Ethics}

The study was performed within the stipulations laid out by the Declaration of Helsinki, and approval was obtained from the Ethics Research Committee of Necmettin Erbakan University.

\section{Disclosure Statement}

The authors declare that they have no conflict of interest.

\section{References}

1 Yilmaz S, Adisen MZ, Misirlioglu M, Yorubulut $S$. Assessment of third molar impaction pattern and associated clinical symptoms in a Central Anatolian Turkish Population. Med Princ Pract. 2016;25(2):169-75.

2 Begtrup A, Grønastøð HÁ, Christensen IJ, Kjær I. Predicting lower third molar eruption on panoramic radiographs after cephalometric comparison of profile and panoramic radiographs. Eur J Orthod. 2013 Aug;35(4): 460-6.

3 Breik $\mathrm{O}$, Grubor $\mathrm{D}$. The incidence of mandibular third molar impactions in different skeletal face types. Aust Dent J. 2008 Dec;53(4): $320-4$.

4 Hassan AH. Mandibular cephalometric characteristics of a Saudi sample of patients having impacted third molars. Saudi Dent J. 2011 Apr;23(2):73-80.

5 Kaomongkolgit R, Tantanapornkul W. Pattern of impacted third molars in Thai population: retrospective radiographic survey. J Int Dent Med Res. 2017;10:30-5.

6 Bashir S, Rasool G, Afzal F, Hassan N. Incidence of mandibular 3rd molar impactions in different facial types of orthodontic patients seen at Khyber College of Dentistry. Pak Oral Dent J. 2016;36:232-4.

7 Hassan AH. Pattern of third molar impaction in a Saudi population. Clin Cosmet Investig Dent. 2010 Oct;2:109-13.
8 Kruger E, Thomson WM, Konthasinghe P. Third molar outcomes from age 18 to 26 : findings from a population-based New Zealand longitudinal study. Oral Surg Oral Med Oral Pathol Oral Radiol Endod. 2001 Aug 92(2):150-5.

9 Capelli JJr. Mandibular growth and third molar impaction in extraction cases. Angle Orthod. 1991;61(3):223-9.

10 Björk A, Jensen E, Palling M. Mandibular growth and third molar impaction. Acta Odontol Scand. 1956;14(3):231-72.

11 Ricketts RM. A principle of arcial growth of the mandible. Angle Orthod. 1972 Oct;42(4): $368-86$.

12 Shehanaz A. The incidence of types of mandibular third molar impactions in different skeletal face types: a clinical study. Int J Orofac Res. 2017;2:24-7.

13 Winter GB. Impacted mandibular third molars. St Louis: American Medical Book Co; 1926.

14 Landis JR, Koch GG. The measurement of observer agreement for categorical data. Biometrics. 1977 Mar;33(1):159-74.

15 Shokri A, Mahmoudzadeh M, Baharvand M, Mortazavi H, Faradmal J, Khajeh S, et al. Position of impacted mandibular third molar in different skeletal facial types: first radiographic evaluation in a group of Iranian patients. Imaging Sci Dent. 2014 Mar;44(1):61-5.

16 Obiechina AE, Arotiba JT, Fasola AO. Third molar impaction: evaluation of the symptoms and pattern of impaction of mandibular third molar teeth in Nigerians. Odontostomatol Trop. 2001 Mar;24(93):22-5.
17 Topkara A, Sari Z. Investigation of third molar impaction in Turkish orthodontic patients: Prevalence, depth and angular positions. Eur J Dent. 2013 Sep;7(5 Suppl 1):S948.

18 Mollaoglu N, Cetiner S, Güngör K. Patterns of third molar impaction in a group of volunteers in Turkey. Clin Oral Investig. 2002 Jun; 6(2):109-13.

19 Gooris CG, Artun J, Joondeph DR. Eruption of mandibular third molars after second-molar extractions: a radiographic study. Am J Orthod Dentofacial Orthop. 1990 Aug;98(2): 161-7.

20 Kim TW, Artun J, Behbehani F, Artese F. Prevalence of third molar impaction in orthodontic patients treated nonextraction and with extraction of 4 premolars. Am J Orthod Dentofacial Orthop. 2003 Feb;123(2):138-45.

21 Svendsen H, Maertens JK. Etiology of third molar impaction. Textbook and Color Atlas of Tooth Impactions. Copenhagen: Munksgaard; 1997.

22 Cassetta M, Altieri F, Di Giorgio R, Silvestri A. Two-dimensional and three-dimensional cephalometry using cone beam computed tomography scans. J Craniofac Surg. 2015 Jun; 26(4):e311-5.

23 Eröz UB, Ceylan I, Aydemir S. An investigation of mandibular morphology in subjects with different vertical facial growth patterns. Aust Orthod J. 2000 Mar;16(1):16-22. 